\title{
A Case report on aneurometabolic disorder: Glutaric aciduria type I
}

\author{
Setareh Sadehal ${ }^{1}$, Peyman Eshraghi ${ }^{1}$
}

\section{ABSTRACT}

Glutaric aciduria type I is caused by an autosomal recessive inherited deficiency of glutaryl-CoA dehydrogenase, which gives rise to the glutaric acid and 3-hydroxyglotoric acidase as well as gluturyl carnitine in body fluid.efected patient can present with macrocephaly and acute dystonia secondry to striatal degeneration following infection and vaccination between 6 and 18 month. Here in, we reported five cases with macrocephaly, dystonia diagnosed with glutaric aciduria type I using the typical brain imaging and tandem mass spectrometry.

Keywords: glutaric aciduria, macrocephaly, dystonia

\section{INTRODUCTION}

Glutaric aciduria type I is an autosomal recessive disorder of the degradation of lysine, hydroxilysine, and tryptophan caused by the defect of the glutaryl-CoA dehydrogenase (1). The prevalence of COA is estimated to be 1 per 100,000 [7]. This disorder is associated with encephulopathic crisis and severe extrapyramidal symptoms. It is characterized with macrocephaly, frontotemporal brain atrophy, and acute encephalopathic episodes, dystonia and many times resembeling seizures at the first episode with degeneration of the caudate and the putamen (2). Early diagnosis and therapy reduce the risk of acute dystonia in patients with GA-1 (3).

\section{CASE 1}

A 13-month-old male infant was admitted to the pediatric hospital in two month's old with upper respiratory infection, vomiting, fever, and seizure. He showed normal values in the following tests: complete blood count (CBC), serum electrolyte, venous blood gases (VBG), prothrombin time, partial thromboplastin time (PTT), cerebrospinal fluid (CSF) collection, and ammonia test.

\section{The computed tomography (CT) scan of the brain showed subdural hemorrhage (Fiqure 1)}

On examination revealed a large head circumference $(\mathrm{HC}: 51 \mathrm{~cm})$ and developmental delay as poor head control and after acute episode disability of sitting or crawling. The metabolic screening of dried blood spots by tandem mass spectrometry revealed elevated glutarylcarnitine levels $(>0.01$, cut off level $<0.006)$, which was suggestive of the glutaric aciduria type I. Subsequently, the child was treated with carnitine, riboflavin, and lysine-free infant formula. After six months of treatment, he could sit with support and remained seizure-free with antiepileptic drugs; furthermore, his head size was stable.

\footnotetext{
1 Department of pediatric endocerinology, Mashhad university of medical sciences, Mashhad, Iran

Correspondence: Peyman Eshraghi

Department of pediatric endocerinology, mashhad university of medical sciences, Mashhad, Iran

Received: 21 Feb 2018, Accepted: 30 Mar 2018

E-mail: eshraghip2@mums.ac.ir
}

(C) 2019 by the authors; licensee Modestum Ltd., UK. This article is an open access article distributed under the terms and conditions of the Creative Commons Attribution License (http://creativecommons.org/licenses/by/4.0/). 


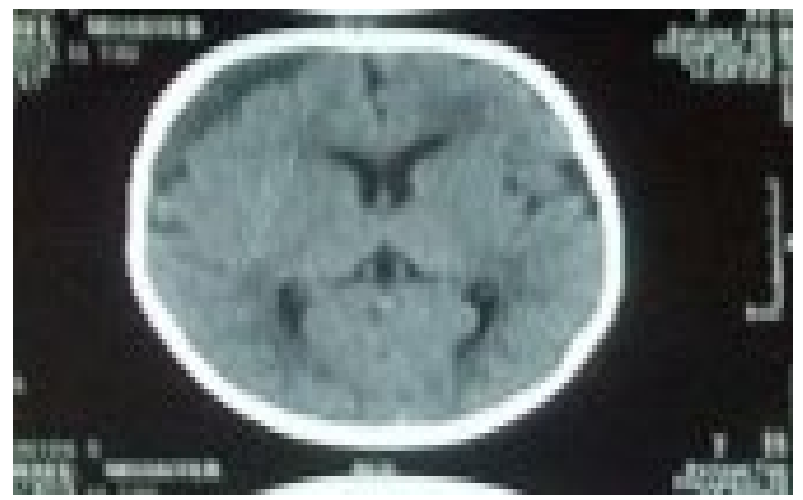

Figure 1: Brain CT showed subdurul hemorrhage

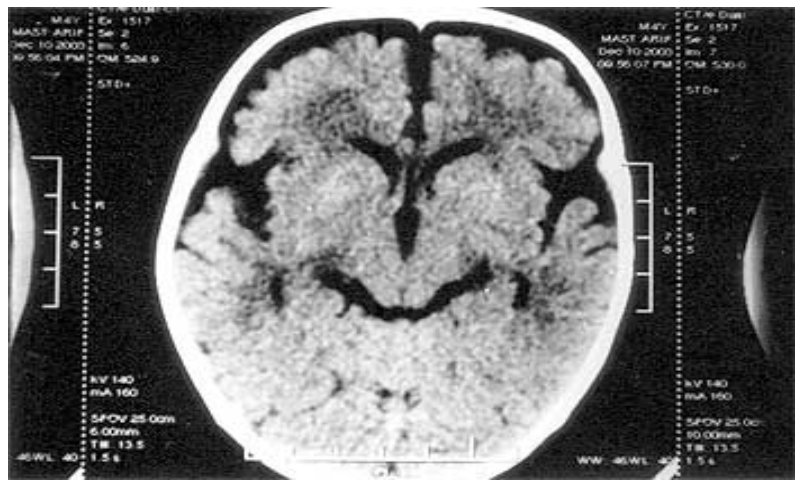

Figure 2: CT scan brain: Widened Sylvian fissure(bat-wing sign)

\section{CASE 2}

A five-year-old male child born of a consanguineous marriage presented with fever, irritability and dystonia after receiving the vaccine at 6 months of age. On the physical examination, he was diagnosed with macrocephaly (HC: $50 \mathrm{~cm}$, birth HC: $34 \mathrm{~cm}$ ). The results of the laboratory tests, including the $C B C$, serum electrolytes, liver function, and CSF were normal. The ammonia level and blood lactate concentration were $110 \mu \mathrm{mol} / \mathrm{L}$ and $18.5 \mathrm{mmol} / \mathrm{L}$, respectively. In the tandem mass spectrometry, $\frac{\text { quturyl curnitine }}{\text { carnitine }}$ was significantly elevated $(0.014$, cut off $<0.002)$.

\section{The brain CT scan revealed a sever frontotemporal atrophy (bat-wing appearance) (Figure 2)}

In the genetic analysis, C0148T > G (PTrp 506ly.Hom) was detected on glutamate dehydrogenase. He was treated with carnitine, riboflavin, and free-lysine formula for 10 months. Currently, he showed delay in motor development; however, the cognitive development was normal; therefore, he had performing regular physiotherapy.

\section{CASE 3}

A 12-month-old male infant was referred to the pediatric hospital at the age of four months with seizure and progressive macrocephaly (HC: $42 \mathrm{~cm}$ ). He showed normal results in such laboratory tests as $C B C$, serum electrolytes, VBG, and CSF. The ammonia level and blood lactate concentration were $195 \mu \mathrm{mol} / \mathrm{L}$ and $77 \mathrm{mmol} / \mathrm{L}$, respectively. The electroencephalograph was also normal.

The tandem mass spectrometry revealed increased glutarylcarnitine level. In addition, the urine organic acid analysis showed elevated glutaric acid and 3-hydroxyglutaric acid levels. In the MRI examination, the temporal atrophy and enlargement of sylvian fissure were detected (Figure 3). His current therapy included receiving carnitine, riboflavin, and lysine-free formula. He was stable in the follow-up and showed increased muscle tone and good head control. The growth parameters were normal (weight: $9 \mathrm{~kg}, \mathrm{HC}: 50 \mathrm{~cm}$ ) and his head size remained fixed; moreover, he can sit only with support. 

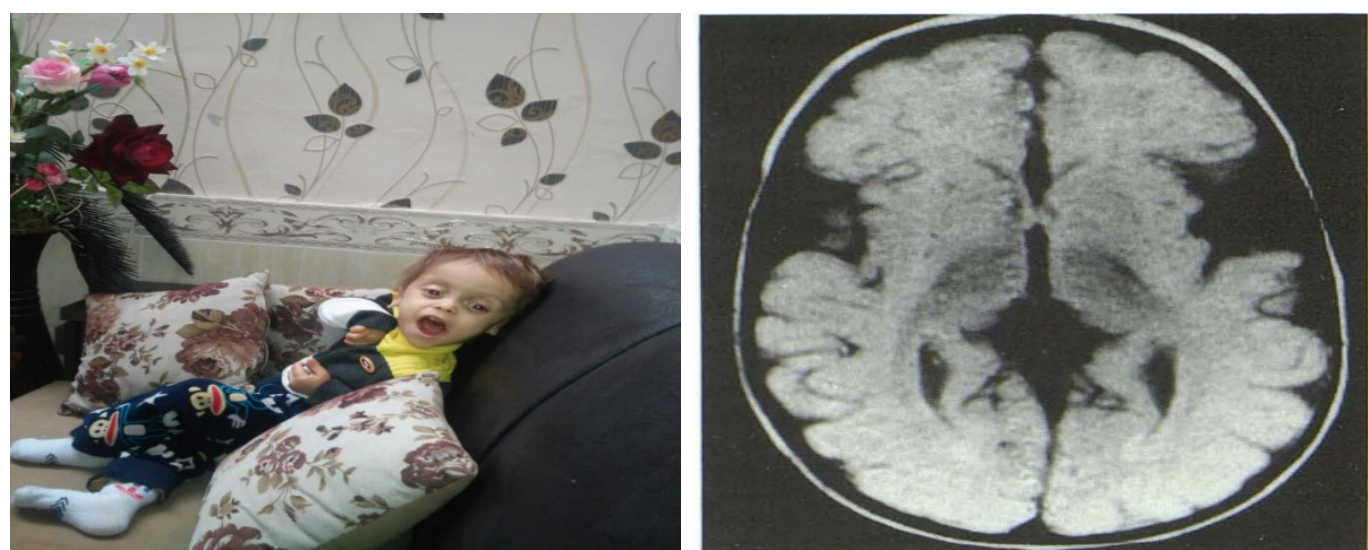

Figure 3: The case 3 after treatment. Brain MRI revealing severe fronto temporal atrophy
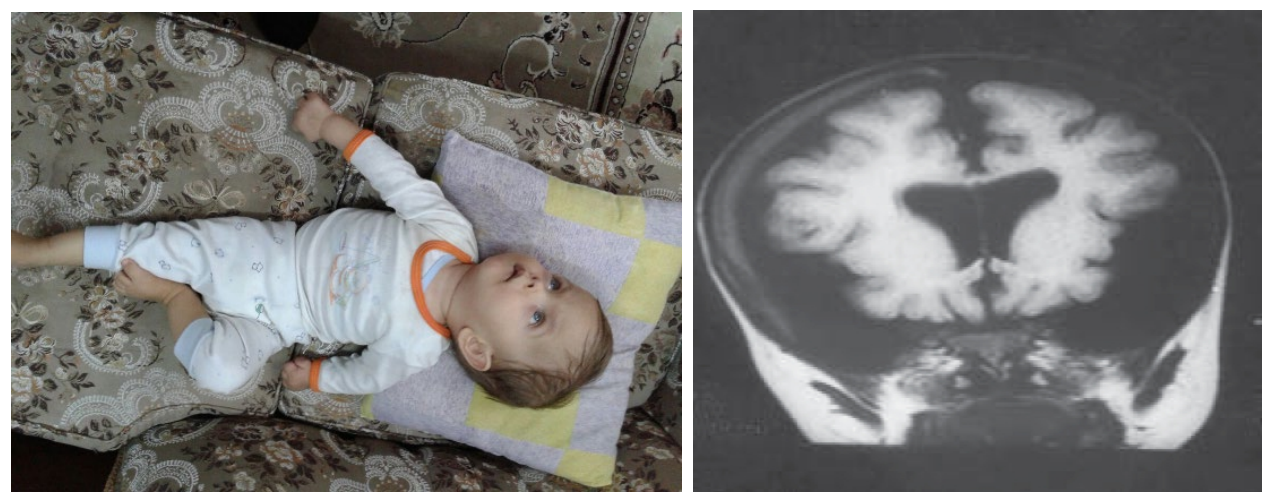

Figure 4: The case 4 in begining of treatment. Flair coronal MR image revealing wide CSF spaces bilateral frontoparietal subdural effusions and atrophy

\section{CASE 4}

This case was a 2-year-old male infant born of consanguineous marriage. He was referred to a pediatric neurologist when he was 3-month-old due to the rapid growth of $\mathrm{HC}$ (37 and $44 \mathrm{~cm}$ at birth and 3-month of age, respectively).

The brain MRI demonstrated bilateral extensive subdural effusion. The urine organic acid analysis revealed elevated glutaric acid $(26.96 \mathrm{mmol} / \mathrm{mol})$, normal cratinine $(<14.7)$, and elevated 3-hydroxyglutaric acid levels (69 $\mathbf{~ m m o l} / \mathbf{m o l} \mathrm{Cr}$ ), which was indicative of glutaric aciduria type I. He was prescribed to use carnitine and riboflavin and have low protein diet and artan. In the follow-up, he stood with support and had, stable head size, decreased dystonia, and little spasticity.

\section{CASE 5}

This case was a 15-month-old female infant born of consanguineous marriage. She presented with head lag and macrocephaly at the age of four months $(\mathrm{HC}=45 \mathrm{~cm})$. The tandem mass spectrometry demonstrated significantly high glutarylcarnitine level $(0.039 \mathrm{mmol} / \mathrm{L}$, cut off level < 0.006$)$, which was suggestive of glutaric aciduria type $\mathrm{I}$. The brain CT scan revealed severe frontotemporal atrophy. She was treated at the age of five months and was stable since then.

In terms of the family history, her uncle had similar symptoms. He had developmental delay and quadripelagia because he had not received the respective diagnostic tests. While she was 11 months old, she was admitted to the pediatric hospital with fever and gastroenteritis. In the follow-up, she showed poor head control and increased dystonic movements despite receiving the necessary treatment and supportive care. 

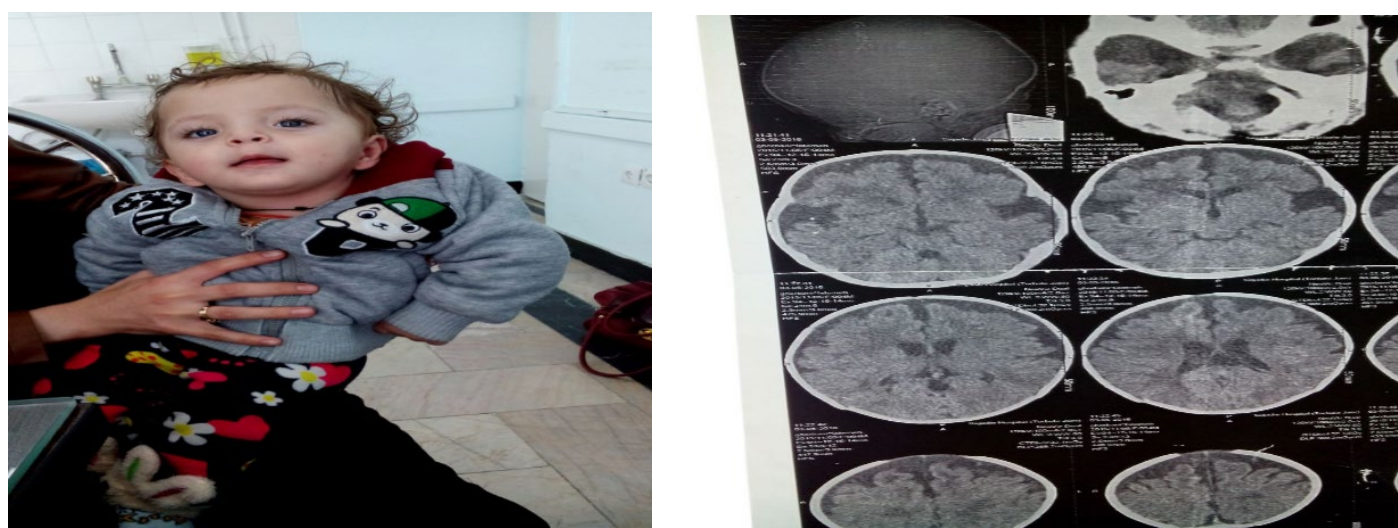

Figure 5: The case 5 after treatment. Brain CT reveals severe fronto temporal atrophy (bat-wing sign)

Table 1: Specification of patients

\begin{tabular}{cccccc}
\hline cases & $\begin{array}{c}\text { Cosanguinity of } \\
\text { parents }\end{array}$ & Age of diagnosis & $\begin{array}{c}\text { Imaging (positive Bat } \\
\text { wing sign) }\end{array}$ & $\begin{array}{c}\text { Hed circumference in } \\
\text { diagnostic time }\end{array}$ & Development delay \\
\hline Case 1 & + & 1 month & - & $51 \mathrm{~cm}(85$ per) & + \\
\hline Case2 & + & 6 month & + & $50 \mathrm{~cm}(95$ per) & + \\
\hline Case3 & + & 4 month & + & $46 \mathrm{~cm}(90$ per $)$ & + \\
\hline Case4 & + & 3 month & - & $44 \mathrm{~cm}(97$ per $)$ & + \\
\hline Case5 & + & 4 month & + & $45 \mathrm{~cm}(85$ per $)$ & + \\
\hline
\end{tabular}

Per: percentile

+ : positive

-: negetive

\section{DISCUSSION}

Glutaric aciduria type I is an inherited metabolic disorder. The use of dietary treatment in combination with L-carnitine and emergency treatment has been demonstrated to be effective in preventing the neurological diseases caused by this disorder. Accordingly, the patients who received all these three interventions (i.e., low lysine diet, carnitine supplementation, and emergency treatment) showed better neurological outcomes (4).

The management of the neurological complications is difficult. Furthermore, the dystonic patients need multidisciplinary supports. Baclofen and benzodiazepines as monotherapy or in combination are most often used as the first line treatment. Administration of pharmacological doses of ribofelavin and supplementation of I-carnitine form the mainstay of therapy. However, even with treatment 25 to $35 \%$ of children with GA-1 develop some level of motor and cognitive impairment (4).

In conclusion, GA is of course not primarily a radio logical diagnosis with highly specific changes. However, any case of unclear hydrocephaly and brain atrophy, basal ganglia changes, and retarded myelination should bring about a strong suspicion of GA-1. For these infants at risk the urine organic acids is simple and can prove GA-1.The encephalopatic crisis can be avoided with its irreversible neurological changes(5). Infact treatment has resulted in delayed progression of radiologic findings and imperfect regression. Serial examinations are important to evaluate the response to therapy (6).

\section{CONCLUSION}

GA-1 is an important neurometabolic disorder in children. We reported five case from GA-1 in our paper. In conclusion all despite therapy whit carnitin and low protein daiet have signe of developmental delay, so early diagnose help to result in a better outcome. Prenatal diagnosis can be made by demonstration of glutaric acid in aminiotic fluid. So we advise routin metabolic deasies screen for all neonate to prevent further deterioration and encephalopathic crisis. This is important in conuseling parents with one affected child in this paper, radiologic finding in all case were not similiar. And Batwingsign were not in all case. So it has been suggested that the combination of radiologic finding and biochemical lab tests are essencial for diagnosis.different studies are needed to establish the best method for diagnosis and beter therapy of this disorder. 


\section{REFERENCES}

1. Hoffmann GF, Trefz FK, Barth PG, et al. Glutaryl-coenzyme A dehydrogenase deficiency: a distinct encephalopathy. Pediatrics. 1991 Dec;88(6):1194-203. PMid:1956737

2. Superti-Furga A, Hoffmann GF. Glutaric aciduria type 1 (glutaryl-CoA-dehydrogenase deficiency): advances and unanswered questions. Report from an international meeting. Eur J Pediatr. 1997 Nov;156(11):821-8. https://doi.org/10.1007/s004310050721 PMid:9392391

3. Baric I, Zschocke J, Christensen E, et al. Diagnosis and management of glutaric aciduria type I. J Inherit Metab Dis. 1998 Jun;21(4):326-40. https://doi.org/10.1023/A:1005390105171 PMid:9700590

4. Pusti S, Das N, Nayek K, et al. A treatable neurometabolic disorder: glutaric aciduria type 1. Case Rep Pediatr. 2014;2014:256356. https://doi.org/10.1155/2014/256356

5. Pfluger T, Weil S, Muntau A, et al. Glutaric aciduria type I: a serious pitfall if diagnosed too late. Eur Radiol. 1997;7(8):1264-6. https://doi.org/10.1007/s003300050287 PMid:9377513

6. Altman NR, Rovira MJ, Bauer M. Glutaric aciduria type 1: MR findings in two cases. AJNR Am J Neuroradiol. 1991 Sep-Oct;12(5):966-8. PMid:1950930

7. Nelson Textbook of pediatrics 19th Edition

$\diamond \diamond \diamond \diamond \diamond \diamond \diamond$

http://www.ejgm.co.uk 